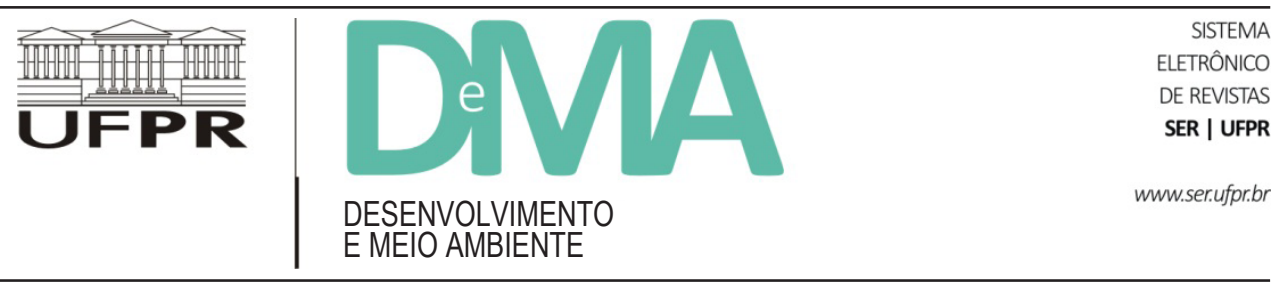

\title{
Hacia un pensamiento socioambiental: aproximaciones epistemológicas y sociológicas
}

\author{
Rumo a um pensamento socioambiental: \\ aproximações epistemológicas e sociológicas
}

\section{Towards an Environmental and Social Thought: Epistemological and Sociological Approaches}

\author{
Dimas FLORIANI ${ }^{1 *}$, Nelson VERGARA ${ }^{2}$ \\ ${ }^{1}$ Universidade Federal do Paraná (UFPR), Curitiba, PR, Brasil. \\ ${ }^{2}$ Universidad de los Lagos, Osorno, Chile. \\ *E-mail de contacto: dimas@casla.com.br
}

Artículo recibido el 16 de octubre, 2015, versión final aceptada el 3 de desembro, 2015.

RESUMEN: En lo esencial, el artículo se propone contribuir al conocimiento de los problemas ambientales desde perspectivas científicas que emanan de la crisis de los paradigmas modernos, como aperturas a la consideración de saberes tradicionales y locales. Para esto sigue un curso en que se destacan dos momentos: primero, el de una fundamentación del conocimiento y de los problemas ambientales en la actualidad. Esta fundamentación releva como significativo el asunto de la confrontación paradigmática y sus respectivos contextos, tanto en lo concerniente a la realidad de los problemas ambientales como a su conocimiento; segundo, el abordaje a la cuestión socioambiental desde un punto de vista filosófico y sociológico con el fin de delimitarlos con relación a la relevancia que estos problemas vienen adquiriendo en las sociedades actuales; en tercer lugar, hacer frente a las diferentes perspectivas del conocimiento científico con otros conocimientos culturales que pueden distanciarse pero también complementarse, por medio de una práctica dialógica de saberes. Cierra el artículo, un apartado a modo de conclusión que abre perspectivas de futuros desarrollos del tema, y una bibliografía que permite seguir los postulados del artículo en sus líneas argumentales.

Palabras clave: conocimiento científico; conocimiento local; paradigma; problemas socioambientales.

RESUMO: No essencial, o artigo propõe-se a contribuir para o conhecimento dos problemas ambientais a partir de perspectivas científicas que emergem da crise dos paradigmas modernos, considerando os saberes tradicionais e locais. Para tanto, conduz a abordagem em três momentos: o primeiro, pela fundamentação do conhecimento e dos problemas ambientais da atualidade. Esta fundamentação destaca, num primeiro momento, como signi- 
ficativo o tema do confronto paradigmático e de seus respectivos contextos, seja em termos de realidade dos problemas ambientais, seja o seu conhecimento; no segundo momento, aborda a questão socioambiental do ponto de vista filosófico e sociológico, tendo em vista a relevância atual desse problema; em terceiro lugar, confronta em diferentes perspectivas os conhecimentos científicos com os demais saberes culturais que podem distanciar-se, mas também complementar-se mutuamente, por meio de uma prática dialógica de saberes. O artigo finaliza abrindo possibilidades para futuras abordagens sobre o tema e apresenta uma bibliografia que permite acompanhar os fundamentos argumentativos do texto.

Palavras-chave: conhecimento científico; conhecimento local; paradigma; problemas socioambientais.

ABSTRACT: Essentially, the article proposes to contribute to the knowledge of environmental problems from scientific perspectives that emerge from the crisis of the modern paradigms, considering the traditional and local knowledge. To this end, the approach will be in three stages: first, by the reasoning on knowledge and today's environmental problems. That reasoning highlights how significant the topic of paradigmatic confrontation and their respective contexts is, in terms of the reality of environmental problems or their knowledge; second, addresses the environmental issue of philosophical and sociological point of view, considering the current relevance of this issue; third, confronting different perspectives of scientific knowledge with other cultural knowledge that can shock but also complement each other, through a knowledge dialogue practice. The article concludes by opening possibilities for future approaches to the topic and presents a bibliography that tracks the fundamentals of argumentative text.

Keywords: scientific knowledge; local knowledge; paradigm; social and environmental problems.

\section{Introducción}

El propósito de este artículo es contribuir a la discusión de problemas que están en el centro de grandes controversias. Nos referimos a los problemas socioambientales en tanto constituyen objeto de ensayos de comprensión e interpretación de nuestra actualidad. En este sentido, nos hacemos parte de la conjetura ya generalizada de que tales controversias son manifestaciones, o síntomas, de una crisis global de la civilización de Occidente en su fase de Modernidad ${ }^{1}$, conjetura que constituye el punto de partida y el supuesto fundamental de estas reflexiones.

Pero esta conjetura nos conduce a otra no menos radical, según la cual esta crisis de civilización tiene su origen en la crisis del tipo de pensamiento ${ }^{2}$ que sostuvo a la Época Moderna, dándole la figura y el sentido de su racionalidad, lo que se puede llamar su "lógica". Llamaremos racionalismo a esa lógica, tanto si se evidencia en el plano intelectual como en el de las acciones a que esa racionalidad conduce. De esta manera la tesis que atraviesa todo el artículo es la de la crisis global del racionalismo moderno ${ }^{3}$ visualizada en algunas indicaciones de cómo se han interpuesto y hasta contrapuesto intentos y propuestas de epistemologías de la diversidad desde el Sur ${ }^{4}$.

En el contexto señalado, el principio de que queremos partir, establece que todo problema de investigación, científico o filosófico, emerge en una situación cultural en que los valores constituyen dimensiones insoslayables, situación en que los problemas son construidos, disputados y legitimados como objetos de conocimiento; es decir, justificados como problemas, articulados en relaciones "disciplinares", situados en sectores o lugares

\footnotetext{
${ }^{1}$ En el siglo XX esta conjetura, en su marco filosófico, puede encontrarse muy desarrollada en el pensamiento de José Ortega y Gasset en sus referencias a las grandes creencias modernas en crisis. Ver bibliografía.

${ }^{2}$ En nuestro tiempo y región, la tesis ha sido muy explicitada en el pensamiento de Enrique Leff. Ver bibliografía.

${ }^{3}$ Incluimos en esta denominación, tanto al intelectualismo como al empirismo en la reflexión de K. Popper, así como su ulterior desarrollo en el positivismo y el neopositivismo contemporâneo.

${ }^{4}$ Sobre la noción de Epistemologías del Sur: Santos, Boaventura de Sousa (2004; 2010).
} 
específicos de lo real, referidos y sostenidos por lógicas y metodologías de investigación sui generis; y, lo que no es menor, apoyados también por una determinada institucionalidad, según la cual los programas y proyectos se validan socialmente; esto es que, de modo formal, son sostenidos por financiamientos económicos y defensas políticas, a lo que se agrega, en términos normativos también, exigencias de administración académica, todo lo cual se asume como sancionado por instituciones de prestigio reconocido 5 . De este modo, la investigación misma, en las formas canonizadas por la sociedad, se institucionaliza y adquiere su carácter sociohistórico, respondiendo de modo característico a una plataforma de exigencias y expectativas en cuyos horizontes se inscribe como acatamientos o rechazos a esas normativas.

Estas exigencias y expectativas pueden ser internas o externas en la investigación. Entre las primeras hay correlaciones epistemológicas (concepciones del conocimiento, lógicas y metodologías de la investigación), y ontológicas o metafísicas (concepciones del ser o de la realidad). Entre las segundas, procesos de emergencia o co-emergencia de problemas que revelan motivos, intereses y racionalidades provenientes de los mundos sociohistóricos; entre ellos, referentes sociales (políticos, económicos) y culturales (antropológicos, religiosos, éticos, estéticos, etc.), de preferencia, el poder ${ }^{6}$.

En suma, para verificar la existencia y consistencia de un campo de investigación, hay que comprender que toda interrogante o resolución científico-humanista aparece siempre en el ámbito y radio de acción de principios y normatividades, que actúan desde modelos consagrados o emergentes, ya sea como críticas a la institucionalidad, o como se dice actualmente, como crítica al ámbito de los paradigmas ${ }^{7}$, lugares o espacios intelectuales en que se conjugan las dos dimensiones referidas. De aquí la importancia que ha adquirido este tema de lo paradigmático en los estudios epistemológicos, tanto para la comprensión del presente y del futuro de las investigaciones, como de su pasado inmediato o lejano ${ }^{8}$.

\section{Cuestiones teóricas generales}

Una primera cuestión general que releva la significación y el alcance teórico y práctico de los paradigmas, es aquella que sostiene la opinión de que no es posible concebir una epistemología al margen de una ontología o metafísica.

Tal opinión habla en dos modalidades discursivas complementarias: por un lado, dice (o refiere) una condición inherente a la investigación, según la cual no se puede pensar el conocimiento sin una referencia a la realidad de aquello hacia lo que el conocimiento tiende, así como, viceversa, no podemos referir algo como real (o irreal) más que en el marco del conocer o del pensamiento que piensa realidades, sobre todo, aunque no exclusivamente, realidades necesarias ${ }^{9}$, en una clara alusión a lo que se ha venido llamando intencionalidad. Por otro lado, refiere a condicionantes que intervienen de modo circunstancial. En razón de la primera, el conocimiento es siempre conocimiento de algo; en razón de la segunda, ese algo lo es con relación a alguien, ante quien es lo que es, o lo que aparenta $\operatorname{ser}^{10}$. Con otras palabras, que nada es en sí y por sí mismo ${ }^{11}$, esto es, absoluto.

Sin embargo, esta relación intencional, requiere de precisiones. En primer lugar, hay que señalar que

\footnotetext{
${ }^{5}$ Por ejemplo, Conicyt en Chile, CNPq en Brasil.

${ }^{6}$ Véase en este contexto las reflexiones ya emblemáticas de M. Foucault. Ver bibliografía.

${ }^{7}$ Por lo pronto consideramos como paradigma a un modelo ejemplar que en lo teórico y lo social rige la práctica científica en un momento determinado aunque en la actualidad el concepto se ha extendido a todo tipo de prácticas.

${ }^{8}$ Véase, por ejemplo, T. Kuhn (1989), E. Morin (2003), F. Capra (2008; 2012), B. de Sousa Santos (2004; 2007; 2010).

${ }^{9}$ Sabemos que el azar es también un tipo de realidades que, desde hace algún tiempo, se ha incorporado a las preocupaciones científicas. Véase al respecto la obra de J. Monod (1993) y F. Jacob (1972)

${ }^{10}$ A la realidad concebida de este modo es a lo que se ha dado el nombre de verdad. De aquí el concepto tradicional que define la investigación científico-filosófica como búsqueda de la verdad de las cosas, lo que habitualmente implica un modo de llegar a ella, o su imposibilidad. Según Fairclough (2008, p. 74-75) interpretando a Foucault, la ‘verdad' se presenta como una operación de enunciados (arqueología) y vinculada a esta como un sistema de poder (genealogía).

${ }^{11}$ E. Morin (2003).
} 
la referencia general, abstracta, recién indicada, no es suficiente; entonces, cada caso debe ser estipulado de un modo concreto: la referencia a la realidad de algo será siempre referencia a una realidad situada, es decir, referida a ésta o aquélla realidad, así como el pensamiento en el que se manifiesta esa realidad será siempre éste o aquél pensamiento, situado también; o sea, pensado por alguien concreto y en términos también concretos, circunstanciados, lo que hace de la intencionalidad una relación intrínseca y extrínseca a la vez.

Una segunda precisión dice que la referencia no debe ser considerada en términos de relaciones de determinación causal, unilineal, sino como una correlación e interdependencia, lo que cambia la metáfora mecánica de la cadena, tan apreciada por la Modernidad ${ }^{12}$, por la metáfora compleja de la red, metáfora que, a nuestro juicio, define bien la actual "configuración" de nuestro mundo. Esto significa que la investigación inquiere no solamente cómo se conocen los problemas, sino también, en qué consisten dichos problemas. Tiene sentido entonces apostar por un diálogo entre el pensamiento y la realidad tal como viene siendo postulado en nuestra época ${ }^{13}$.

Pero, el asunto no es sencillo, ya que realidad y conocimiento no son cuestiones dadas, espontáneas, conformadas por algo así como la naturaleza ${ }^{14}$ de las cosas, una suerte de condición fija e invariable que se expresaría en la noción de "ley de las cosas", sino que en lo fundamental, realidad y conocimiento pertenecen al mundo de la historicidad ${ }^{15}$, lo que se evidencia en los cambios de la idea y práctica de la ciencia y de los objetos científicos, y que en cada momento de la historia del pensamiento conceptual se ven reflejados en las transformaciones de los símbolos que los expresan y de los paradigmas que los sustentan y representan ${ }^{16}$. Entonces, el camino de una epistemología y de la metafísica que le es coherente como teoría de lo real, es tan complejo como el de la historia de la ciencia misma con que se correlaciona $^{17}$, toda vez que implica mirar la ciencia desde distintas perspectivas (filosóficas, históricas, sociológicas, antropológicas, etc.). ${ }^{18}$

Es claro, sin embargo, que esto no puede ser comprendido de cualquier manera; menos aún de aquélla que es típica del pensamiento lineal, dicotómico y disyuntivo de la Modernidad, en cuyos contextos la relación entre ser y pensar se da en forma de secuencias que, en rigor, son relaciones de consecuencias. Por el contrario, nosotros estamos en la idea de que, en razón de las citadas intencionalidad y complejidad, ambas dimensiones (la del ser y la del pensar) son correlativas también, y que, se dan al mismo tiempo, en un diálogo y recursividad permanentes ${ }^{19}$.

Sin embargo, en esta panorámica que nos procura un diagnóstico de la actual situación epistémica, nos

\footnotetext{
${ }^{12}$ Confróntese "las largas cadenas de razones" que tanto entusiasmaron a Descartes. Ver Meditaciones metafisicas.

${ }^{13}$ En Latinoamérica este diálogo tiene a lo menos dos expresiones claves: el diálogo intercultural, de acuerdo a las ideas de Raúl Fornet-Betancourt (2004), y el diálogo de saberes, según las ideas de Enrique Leff (2004).

${ }^{14}$ Como todos los grandes conceptos, este de "naturaleza" está en el centro de una discusión de larga data en occidente y responde a cuestiones contextuales que la explicitan y justifican. .Una formulación de gran alcance proviene de Aristóteles. Otra, moderna, la encontramos en Marx. Posteriormente, Weber, Ortega y Foucault, entre otros, han reflexionado sobre esta categoría capital del pensamiento de Occidente. Al respecto, consúltese el texto sobre Modernidades Múltiples de Dimas Floriani (2011).

${ }^{15}$ J. Ortega (1962a, 1962b), A. Koyré (1981).

${ }^{16}$ Contrástese por ejemplo la ciencia llamada galileana-newtoniana con la ciencia eisteiniana, o la confrontación de ciencias naturales y sociales en el pensamiento positivista y el pensamiento del racionalismo crítico.

${ }^{17}$ Nuestros planteos rescatan concepciones de ciencia cercanos a Prigogine, Morin, Fayerabend, Stengers, Castoriadis y Bourdieu, sin descartar aportes importantes del debate protagonizado por Popper, Kuhn, Lakatos, Bohm,Polanyi y por el constructivismo social (Latour). Además, hay que mirar momentos importantes de ruptura entre concepciones de la ciencia normal y post-normal, situaciones nuevas de reintegración de saberes (diálogo de saberes entre conocimientos científicos y no científicos) y la posibilidad de confrontación entre epistemologías logocéntricas (europeas o nórdicas) con las epistemologías culturales o interculturales (desde el sur).

${ }^{18}$ Pero, no se van a considerar aquí todos estos aspectos, sino solamente aquéllos que se reportan en una concepción de la ciencia como un campo autónomo, aunque, como hemos señalado, no independiente de los procesos de conocimiento, culturalmente arraigados en la historia de las sociedades y de cuyos contextos recibe influjos y devuelve formas particulares de representación e interpretación del mundo y del saber mismo. ${ }^{19}$ Ser y pensamiento solo cobran existencia por medio de un sistema de prácticas que no es solo del orden del hacer y de los conflictos políticos que este conlleva, pero también de la producción de objetos materiales e inmateriales. Deleuze (1992, p. 158-162) nos advierte acerca de los intercesores que son dispositivos o sistemas de agenciamientos que se interponen entre el mundo humano imaginado (pensado) y los objetos
} 
parece significativo destacar que en las citadas dialógico y recursividad entre el ser y el pensar, es siempre este último el que inicia el diálogo ${ }^{20}$. Así lo prueban los momentos de cambios sociohistóricos reconocidos sin excepción desde la antigüedad clásica griega hasta la crisis de la Modernidad ${ }^{21}$. En definitiva, esto significa que no hay cambio relevante en la idea de realidad que no esté precedido por un cambio igualmente relevante en la idea del pensar ${ }^{22}$.

En resumen, nuestro planteamiento parte, del presupuesto de que una cierta concepción del conocimiento dispone y condiciona, aunque no determina, la construcción del objeto de investigación en el orden de su realidad, y por lo tanto, también las preguntas recurrentes de la misma y, por ende, implica que los resultados obtenidos dependerán en buena medida de las situaciones y de los medios empleados, cuyas metodologías son encauzadas por procesos solidarios con ciertas teorías sobre las dinámicas naturales y sociales y sus condicionamientos mutuos, recíprocos o no ${ }^{23}$.

Pero, entonces, hay que tener presente que, al mismo tiempo que el conocimiento sirve para instalar y/o develar procesos significativos (por ejemplo, sociales, históricos, globales, locales, científicos o cotidianos, etc.), sirve también, en estos mismos procesos, para construir, consciente o inconscientemente, trampas que pueden velar los sentidos de los objetos o del mundo, ocultándolos, reprimiéndolos y, eventualmente, falseándolos ${ }^{24}$. De allí que esté justificado, a fin de develar sus sentidos, el intento de investigación de las teorías y prácticas de reglas y juegos de lenguaje ${ }^{25}$, a los que cabe agregar cuestiones de imaginarios como la ideología y la utopía según el pensamiento de P. Ricoeur, o de otras formas de la imaginación social como lo han establecido los aportes de Bachelard, Durand, Morin, Castoriadis, etc., todas cuestiones de gran interés y relevancia en los estudios de la investigación contemporánea.

Lo anterior conduce a otro asunto relevante que nos interesa destacar en esta aproximación preliminar, el que se articula con la situación de concepciones del conocimiento científico todavía presentes, pero ya en proceso de transición hacia otras epistemologías que, según nuestro parecer, se encuentran en tránsito hacia nuevas identidades cognoscitivas. El valor de estas consideraciones nos parece que se revela precisamente en sus contrastes. Así, sabemos que las lógicas disciplinares, tributarias del pensar moderno, producen objetos de conocimiento en que éstos aparecen aislados de los demás, fragmentados y parciales, y casi siempre de modo individual, sin un control colectivo de investigadores. ${ }^{26}$ Por otro lado, procesos concebidos como alternativos (actualmente multi/ inter/trans-disciplinarios) construyen objetos asumidos como complejos, compartiendo la búsqueda de resultados desde una mirada colectiva y plural en torno del

que lo constituyen, generadores de creatividad, una vez que pueden ser al mismo tiempo personas - filósofos, artistas, científicos, personas comunes - y cosas, plantas, animales, etc. Partiendo de la idea de que distintos sistemas, por ejemplo, del arte, de la ciencia y de la filosofía (y agregamos además por nuestra cuenta los sistemas culturales y de valores), aparentemente independientes y que, sin embargo, establecen relaciones de resonancias mutuas y de interferencias (lo que Deleuze llama de 'transformación del panadero' cuando prepara la masa para el pan, mezclando materia orgánica, química, espacio y formas por la acción ejercida). Lo mismo se puede decir de los 'intercesores' que mezclan y percusionan pensamientos y realidad.

Un hilo interesante de ser seguido en este debate de los 'intercesores' o mediadores entre dimensiones del pensamiento y la realidad es la discusión que Felix Guattari (1982) y Deleuze \& Guattari (2004) presentan por medio de la oposición entre lo molar y lo molecular por donde se establece una tensión permanente entre las estrategias de captura (de parte de las instituciones) y de flujos (de parte de las estrategias moleculares de los sujetos individuales y colectivos).

${ }^{20}$ A. Koyré (1981; 1994).

${ }^{21}$ K. Popper (1983; 1992), C. Castoriadis (2007).

${ }^{22}$ E. Leff $(2004 ; 2007)$

${ }^{23}$ En este punto, el asunto clave que interroga acerca de si el pensamiento es ya un conocimiento que interpreta aspectos de la realidad del objeto y que para dar lugar a esa interpretación le es necesario reorganizar el conocimiento elaborado sobre otras bases, tiene desde ya una respuesta afirmativa, ya quenada surge en el vacío conceptual, o cultural.

${ }^{24}$ Asunto que comprueba que el pensamiento científico también es afectado por la ideología.

${ }^{25}$ Esto es fundamental por cuanto si estimamos que los problemas son en definitivas construcciones sociales, tal construcción no es posible sin la intervención de la institucionalidad instalada por el lenguaje, probablemente la institución que es la base histórica de todas las demás.

${ }^{26}$ A esta propensión se refiere E. Morin con la categoría de paradigma de la simplicidad (Cfr, 2003, Parte 3). 
objeto en construcción. Por esto, la alta contaminación interdisciplinaria es definida ahora como un elemento positivo, a diferencia de la baja contaminación provocada por una construcción cognitiva disciplinar, donde uno o muy pocos observadores se acercan al mismo objeto y siempre desde campos disciplinares autónomos. Por lo mismo que, por retroefecto, las múltiples miradas hacia los objetos complejos deben ser sostenidas por distintos $\mathrm{y}$ tramados saberes en dirección inter o transdisciplinar ${ }^{27}$.

Conviene entonces abordar las trayectorias de las ciencias en la modernidad, identificar sus fundamentos y contrastarlas con las proposiciones alternativas que emergen de otras "lógicas de investigación", que recientemente se están abriendo a la consolidación de nuevos sentidos teóricos y prácticos. $\mathrm{Y}$ a pesar de no aparecer claramente todavía los dibujos consolidados de esos nuevos paradigmas, cabe suponer que estamos frente a la emergencia de propuestas epistemológicas (y metafísicas) inéditas, en especial aquéllas que señalan hacia problemáticas construidas en las interfaces de los sistemas naturales y de los sistemas sociales ${ }^{28}$. Con esto, las fronteras o límites de las ciencias tienden a diluirse y a desaparecer, así como desaparecen los límites disciplinares y sus exigencias de metodologías unívocas y singulare ${ }^{29}$. En esto, uno de los temas centrales de las nuevas epistemologías y sus metafísicas correspondientes, es aquél que cuestiona fuertemente la distinción y el valor atribuido a lo objetivo frente a lo subjetivo, y a una de sus consecuencias fundamentales como es la teoría de la representación ${ }^{30}$. El desarrollo de un pensamiento ecológico ${ }^{31}$ y su consecuente metodología ilustra bastante bien los derroteros actuales de estos nuevos paradigmas $^{32}$.

Partamos entonces del contexto de estas cuestiones fundamentales y preguntemos: ¿de qué hablamos cuando hablamos de problemas socioambientales y cómo es posible el conocimiento de ellos?

\section{La cuestión socioambiental}

Considerando que en rigor un concepto es un conjunto de referencias significativas a algo tradicionalmente concebido como objeto, éste de lo socioambiental es una especie de un género cuyo referente parece ser $l o$ ambiental sin más. De modo que una primera aproximación a lo socioambiental pasa por una dilucidación de lo propiamente ambiental. Pero, ¿hay en realidad lo ambiental sin más en un orden empírico o conceptual? Someramente podemos establecer que el concepto ambiental se refiere a procesos que pueden definirse como un complejo sistema de interrelaciones. Si sustantivamos el término "ambiente", entonces, "lo ambiental" es una condición y proyección de aquél, es decir, una manifestación del ambiente. Pero, entonces, y en primer término, ¿qué queremos señalar con esta noción de ambiente?

Sin duda que desde las exigencias de un pensamiento complejo, debemos evitar pensar el ambiente como si fuese una cosa, es decir, algo perfectamente determinado, delimitable por sí, autónomo e invariable como fueron pensadas las cosas en el pensamiento moderno, se trate de cosas extensas o de cosas pensantes según lo propuso R. Descartes. En este sentido, asumimos la idea de que nada es en realidad una $\cos a^{33}$, ya que nada está verdaderamente aislado, ni siquiera simplemente conectado, sino que interconectado y forma parte de redes de referencias, en cuyas tramas se van configurando los objetos, sea en interrelaciones sensibles o inteligibles. Pero, del mismo modo, y al mismo tiempo, en estos procesos se configuran también, lo

\footnotetext{
${ }^{27}$ Corresponde a lo que E. Morin llama "paradigma de la complejidad" (2003), Parte 3.

${ }^{28}$ Por ejemplo, los llamados "espacios intersticiales".

${ }^{29}$ En lo fundamental las diferencias teórico-metodológicas señaladas en los últimos párrafos pueden comprenderse como producto de la confrontación de los paradigmas de la simplicidad (modernos) y de la complejidad (contemporáneos) que ha sido tratado en detalle por E. Morin en la obra y capítulo citado.

${ }^{30}$ F. Varela $(2000 ; 2011)$.

${ }^{31}$ Cfr. de F. Capra (2012) y de F. Varela (2000).

${ }^{32}$ Muy relevante en esto nos parece ser la emergencia y desarrollo sostenido que actualmente presenta lo que con mucha propiedad podemos llamar Pensamiento Latinoamericano.

${ }^{33}$ J. Ortega (1962a), E. Morin (1996).
} 
que se ha solido llamar sujetos, de manera que sujeto y objeto son siempre realidades con la misma extensión, complementarias, nunca opuestas y excluyentes.

Entonces, nociones tradicionalmente pensadas como dicotomías, deben ser pensadas hoy en términos de interrelaciones e interdependencias; por ejemplo, las tradicionales materia y conciencia, naturaleza e historia, individuo y sociedad, ser y pensar, etc., tienen necesidad de ser conceptuadas como series o redes de mutuas significaciones, en los que junto con la diversidad y distinción, deben ser aprehendidas también en su unidad relativa y mutuas complementariedades ${ }^{34}$.

De este modo, el ambiente no es algo que está simplemente ahí, como una suerte de receptáculo en el que ingresan y salen cosas, o suceden cosas, sino algo cuyo dinamismo puede ser definido como un conjunto de interrelaciones del hombre y sus entornos y de los hombres entre sí, en cuales quiera de sus referencias ${ }^{35}$. La propia naturaleza, así como la sociedad y la cultura, forman parte del ambiente, tanto en sus dimensiones físicas como en sus referencias simbólicas.

Por lo tanto, la naturaleza no es algo aparte de la sociedad, como ésta no lo es de la historia. Todo es parte de algo y no se puede entender sino como procesos cuyas dinámicas se condicionan entre sí. ${ }^{36}$

A partir de esta noción general, podemos entonces deducir la consistencia de conceptos específicos como puede ser el de lo ambiental, que se asume como una realidad adjetiva: una condición emanada como propia del ambiente. Entonces hablamos de lo ambiental como una realidad sui generis que refiere a condiciones específicas, lo que prueba que tampoco los conceptos tienen una significación en sí, propia e inmutable.

Pero aquí hablamos del ambiente como fuente de conceptos que refieren a relaciones complejas que son identificadas como medio ambiente o medio ambiental, socioambiente o socioambiental, cuestión que nos pone en la necesidad de hacer evidente la realidad a que estos conceptos señalan. Así, con estas precauciones preguntamos de nuevo: ¿de qué hablamos cuando decimos de algo que es un asunto o un problema socioambiental? Con otras palabras, ¿en qué consisten esos problemas?

Anthony Giddens (1997) dibuja un escenario desde el cual lo ambiental emerge como un signo negativo de la modernidad, es decir donde las amenazas y riesgos (Beck, 2010) de las sociedades industriales o productivistas parecieran quitarle el brillo y el éxito a las promesas de progreso y de fantasía hacia un mundo edénico incontablemente infinito, representando así una idea de una segunda caída, en que el hombre fue expulsado del paraíso, y de esta vez por exagerar en las formas de explotar a la naturaleza, exponiéndose a su extinción y no tan sólo por su concupiscencia y pérdida de inocencia, como en la primera expulsión, según la mitología cristiana. Ya no se habla más de una naturaleza virgen ni intocada, pero sí de una segunda, tercera... naturaleza mediada por la técnica y la artificialización de los medios de vida en sus distintas formas de reproducción. Pero hay más, como veremos en lo que sigue.

Teorías y conceptos han sido creados para entender las distintas manifestaciones de una naturaleza culturalmente representada y recreada, desde la ecología pura y la ecología política, las ciencias humanas y sociales, el cine, la literatura y las resignificaciones desde cosmologías orientales, africanas y latinoamericanas. Las teorías eurocéntricas con matrices iluministas, positivistas y otras aún han intentado desde una pluralidad de concepciones filosóficas en sus fundamentos (funcionalismo, estructuralismo, marxismo, fenomenología, vertientes culturalistas de la geografía y antropología, economía neoclásica, ecosociodesarrollo, economía ecológica, modernización ecológica, metabolismo social, teoría de la coevolución, teoría política verde...) delinear los modelos de pensamiento y de consecuencias a nivel de

\footnotetext{
${ }^{34}$ J.P. Sartre (1961)

${ }^{35}$ A ejemplo de las ideas de 'ambiente', 'naturaleza', 'sociedad', 'ciencia', la noción de 'hombre' no está dada simplemente por una referencia genérica a la humanidad. Convendría interrogarse acerca de cómo se (des)construyen los signos y sus significados, pues sufren confrontaciones de orden político, jurídico, filosófico, axiológico... desde distintos 'lugares de enunciación' como dicen los posmodernos. Particularmente aleccionador para develar los nuevos significados de la noción de 'hombre' es el debate planteado por la epistemología feminista y de género (Longino, 2008).

${ }^{36}$ C. Castoriadis (2007).
} 
la producción material y cultural y los distintos niveles de intervención económica, política y tecnológica de parte de los agentes sociales.

A la vez y a la par de estos brotes hermenéuticos centrales, en los bordes del sistema mundo, es decir, del mundo colonizado, emergen formas autóctonas de pensar y de vivir que a pesar de ubicarse como subalternidad frente al sistema hegemónico, reivindican una condición de resistencia y el derecho a argumentar y a dialogar con los demás sistemas de pensamiento, desde una perspectiva de la diferencia y de la diversidad cultural, pero también con autonomía y soberanía epistemológica desde el Sur (Leff, Quijano, Mignolo, Escobar, Sousa Santos, Toledo...).

A lo ambiental se le agrega lo socioambiental al incorporar la multiplicidad de fenómenos, pensamientos y valores intrínsecos a la relación sociedad-naturaleza. De esta manera, se engendran mecanismos cognitivos, políticos y culturales en las teorías que piensan la cuestión socioambiental, desde miradas y prácticas productivas del conocimiento ancladas en metodologías híbridas y novedosas como las de la interdisciplina y de la transdisciplina, en que ya no se habla con susurros de los derechos de la naturaleza y de los parlamentos de las cosas (Latour, 2004), según concepciones ecocéntricas $\mathrm{y}$ del constructivismo radical.

La cuestión socioambiental se politiza entonces en el debate sobre desarrollo sustentable o sustentabilidad. De allí se configuran las disputas no solo hermenéuticas (después de todo ¿qué es sustentabilidad y para qué y quienes sirve?) sino también geopolíticas en escala internacional, nacional, regional y local, en que distintos actores asumen sus concepciones, intereses y posiciones en distintos marcos del conflicto por la apropiación, uso de la naturaleza y la reivindicación de los derechos culturales y de pertenencia a distintas identidades étnicas.

Todos estos fenómenos, visiones, valores e interpretaciones de la naturaleza y de una cultura manipulada por el mercado, pero también de resistencias y conflictos, emergen y ganan espacio en las universidades, sindicatos, organizaciones no gubernamentales y en los colectivos que reivindican esta condición de resistencia en la subalternidad y con pertenencias a identidades étnicas críticas y de contestación al modelo de gestión de los territorios y de sus derechos interculturales.
Pero hemos afirmado que la determinación de la realidad de lo socioambiental nos impone también la tarea de su conocimiento. ¿Cómo asegurar que estamos en camino de conocer ese tipo de realidades complejas?

Debería ser evidente que así como el conocimiento de las realidades en el sentido moderno se realizaba mediante el ejercicio del pensar analítico, discernidor, reductor y disyuntivo, el saber de las realidades complejas de las que el ambiente y lo socioambiental son expresiones, debe convocar un pensamiento complejo también, un pensar que descubre interrelaciones y no datos, interacciones y no determinaciones, interdependencias y no autonomías, codeterminaciones y no condicionamientos lineales; en suma, correferencias e influencias mutuas.

Así, desde la posición que estamos esbozando, las nociones de objetivo y subjetivo como conceptos o realidades antagónicas e irreductibles, deben ser pensadas en contextos que apunten al diálogo y la complementariedad, por lo que estos términos deben ser radicalmente redefinidos. De esta manera ninguno de los términos tiene autonomía sino que se destaca como tal con referencia al otro. Lo dicho es perfectamente aplicable a sus términos correlacionados, como subjetividad y objetividad, subjetivismo y objetivismo, etc. Con otras palabras, nos pone un gran desafío, ya que obliga a pensar no propiamente la conexión, sino la interconexión, el entre.

Entonces, ¿cómo pensar lo socioambiental de modo que podamos decir con propiedad que estamos en presencia de un genuino pensamiento socioambiental?

Por lo visto, no hay cómo pensar correctamente la relación entre los sistemas naturales y los sistemas sociales si no se considera una teoría del conocimiento anclada en bases distintas al paradigma que parte de la fragmentación de la realidad, con la justificación de que sólo es posible conocerla si la descomponemos en cuántas partes uno la imagina estar constituida.

Desde este punto de partida, uno se obliga a una doble concesión, sea con la pretensión o presunción del conocimiento de que todo se ve, a partir de lo que simplemente existe, ya anunciada por Maturana \& Varela (2007) sea cediendo a las formas de legitimación de los procedimientos del poder de las ciencias, tales como se han presentado desde ahora, por la manera de gestionar y reproducir una cultura de organización del conoci- 
miento, como lo vivenciamos en nuestras instituciones académicas, o sea de una cartografía o arquitectura de la disposición de los territorios segmentados de las facultades, sectores, departamentos, laboratorios y sus administraciones.

Es decir, los territorios académicos no son más que expresión o síntoma de algo que está más entramado e involucrado en las teorías y métodos de los conocimientos especializados que conforman los sectores y departamentos de las ciencias de la naturaleza, de la vida, de la sociedad, las tecnociencias ${ }^{37}$, las artes, las humanidades, letras y literatura, las ciencias aplicadas (económicas, contables, jurídicas, arquitectura, comunicación, etc.).

Tampoco hay cómo rehacer el camino de la construcción de un pensamiento genuinamente socioambiental sino por la crítica radical a los fundamentos epistemológicos de la idea de ciencia, de sus prácticas y de una ética de su pertinencia y a quiénes y para qué sirve; por supuesto que ello conlleva a una nueva alianza con los demás conocimientos que emergen del bien cuidar y del buen vivir; una ciencia de los tiempos lentos, que hace alargar el presente y achicar el porvenir, según nos dice Boaventura de Sousa Santos (2004), o a una reinvención de la ciencia moderna por lo que nos indica Isabelle Stengers (2002).

La construcción de un pensamiento socioambiental consiste entonces en abrir espacio a la crítica política en orden a enjuiciar los modelos productivistas de las modernas sociedades que cambiaron la idea de desarrollo por la del crecimiento económico, sometiendo todas las demás dimensiones de la realidad a la sobre economía de las relaciones sociales y culturales. Hoy día una economía que no crece es mirada con desconfianza y juzgada por los medios de comunicación como ineficiente, peligrosa y que pone en riesgo los actuales niveles de consumo, por supuesto, insustentables, pues miran hacia un horizonte de hiperconsumo y del despilfarro de los recursos naturales finitos.

Por lo anterior estimamos que el desafío de la construcción de una epistemología ambiental que posibilite la emergencia de un pensamiento genuinamente socioambiental debe buscar formas híbridas (Leff, 2004; 2008), en base a la diversidad de los conocimientos acerca de la naturaleza, de sus usos y de su coexistencia con modelos de desarrollo que inviertan los términos de la actual ecuación, ponderando los factores y los pesos de la racionalidad instrumental y economicista, hacia una racionalidad ambiental propuesta por Enrique Leff (2004).

En este sentido, es necesario indagar acerca de la pertinencia de aproximar los conocimientos científicos a los demás conocimientos culturalmente arraigados, para intentar desplazar la inercia hacia zonas de fronteras, permitiendo así concebir, desde otras lógicas, la relación entre el sistema naturaleza y el sistema sociocultural, es decir, lejos de las actuales maneras de concebir la realidad y de actuar en ella.

Más todavía: si estamos operando con las interconexiones en la perspectiva de una epistemología multidimensional (híbrida, de la diversidad, cultural, periférica, descolonizada, subalterna, o no importa que adjetivos más le agreguemos) tendríamos que identificar el contra-movimiento epistémico que se insurge desde el Sur y toda la experiencia de los últimos 25 años no sólo en Latinoamérica, sino que también en África y Ásia, pero fundamentalmente en América Latina que ha aportado importante contribución en el dominio de las etnociencias (Argueta Villamar,2012; Toledo y Barrera-Bassols, 2008) de los saberes culturales de las poblaciones tradicionales e indígenas y de los diálogos de saberes e interculturales.

Ha distintas posiciones teóricas y políticas acerca del mosaico que compone este movimiento epistémico del sur, desde situaciones en que investigadores impulsan diálogos y complementariedades entre los conocimientos (científicos y no científicos), hasta movimientos sociales que simplemente rechazan los conocimientos y técnicas de la ciencia occidental. Sin embargo, detengámonos por un momento en la siguiente situación: un argumento hasta cierto punto tautológico acerca de la justificación de por qué el pensamiento eurocéntrico tiene pretensiones de universalidad y si se mira como tal es porque ha

\footnotetext{
37 “El término ‘tecnociencia’ lo usó Bruno Latour en 1983 tan sólo para abreviar la interminable frase de 'ciencia y tecnología’. Otros muchos autores han usado ese mismo término de manera omnicomprensiva. En resumen, hoy en día, para todos, la convergencia entre ciencia y tecnología es tan profunda que todo es tecnociencia" (Javier Echeverría, 2005).
} 
sometido a sus sociedades modernas a una homogeneidad y de la misma manera al colonizar las sociedades periféricas ha extendido esta misión civilizatoria (de la ciencia, de la religión, del poder político y del mercado) a las demás culturas del planeta.

En consecuencia, si uno se fija en la dificultad de manejarse con tal simplificación de una propuesta de este tipo, es muy probable que el punto ciego de una epistemología universal no tiene cómo dar cuenta justamente de la diversidad cultural y de saberes heterogéneos y por ende de la necesidad de incorporar esta diversidad en el marco de un pensamiento híbrido, complejo y plural. Para ello, tendremos que detenernos por algunos momentos en la reflexión acerca de lo que significa introducir otros tipos de experiencias y prácticas dialógicas para hacer emerger una epistemología de la diversidad, desde los diálogos de saberes (Floriani, 2007). Entonces, ¿cómo sería posible imaginar, o mejor, establecer un nuevo contrato epistemológico entre los saberes científicos y no científicos? ¿Se trata de un brote populista en la ciencia, un capricho de intelectuales críticos al sistema hegemónico de ciencia, moral y políticamente involucrados con los movimientos y organizaciones sociales alternativos? ¿Trucos políticos e ideológicos de sectores rezagados y subalternos de las sociedades contemporáneas? O aún ¿vestigios de una modernidad que no alcanzó todavía establecer homogeneidad en todas las actividades productivas y en el modo de vivir incluyendo al mercado por el consumismo tecnológico, cuya expresión más evidente son los estilos de vida urbano, los mall, los transportes urbanos individuales, los smartphones, los usos de comunicación virtual, etc.?

El próximo apartado se compromete con el tema de la pluralidad de conocimientos, de acuerdo a una epistemología crítica y vinculada con la diversidad, la diferencia y el intento de no valorar de antemano si el conocimiento científico es mejor o peor que los demás conocimientos. Según afirman a este respecto Sousa Santos, Meneses \& Nunes "es cada vez más evidente que la reivindicación de carácter universal de la ciencia moderna es sólo una forma de particularismo, cuya particularidad consiste en tener poder para definir como particulares, locales, contextúales y situacionales todos los conocimientos que con ella [la ciencia moderna] se confrontan" (2005, p. 55).

La especialización del conocimiento científico no significa tan sólo la necesidad de una mejor y mayor profundización de las múltiples disciplinas existentes, sino que conlleva la separación entre los científicos y los legos e introduce otros componentes al qué hacer científico que no son necesariamente del orden estrictamente racional como lo exige la ciencia, sino que responden a una valoración e imperativos del poder, es decir que la ciencia se impone como legitimadora y es legitimada por los mecanismos sociales, económicos, culturales instituidos por las agencias académicas, por el mercado, la media y las comunidades epistémicas, además de quitarle valor e importancia a todos los demás conocimientos y saberes culturales (populares) ${ }^{38}$ considerados como "tradicionales" o inferiores, pues considera que estos no se traducen en sofisticadas tecnologías.

El intento de reinvención de los demás conocimientos por la acción de visibilización de un gran número de distintos actores sociales, involucrados con prácticas y sistemas culturales diversos, reintroduce el fundamento epistemológico de la pluralidad y la diferencia entre saberes que en lugar de operar como ejemplares de la 'gran división intelectual del trabajo científico', condicionado por las especializaciones científicas, sirven más bien, en muchos casos, para generar complementariedades más que competencia entre conocimientos científicos y no científicos.

En otros casos, tenemos inconmensurabilidades, es decir, incompatibilidades. Con todo, no hay porqué eliminar o silenciar los saberes en nombre de una racionalidad que se estima a sí misma como superior. Además, no se trata de plantear este 'conflicto de racionalidades' solamente del punto de vista interno de la epistemología o

\footnotetext{
${ }^{38}$ Por saberes culturales, entendemos las distintas formas de producir conocimiento, sea en sus dimensiones materiales (prácticas) y simbólicas (ideológicas) en sus más diversas modalidades (religiosas, estéticas, morales, económicas, técnicas, afectivas, discursivas, del sentido común, artísticas, etc.) lo que incluye el desarrollo de visiones, mitos, e imaginarios acerca de la naturaleza, lo cotidiano, los territorios y la reinvención de las memorias colectivas, etc.
} 
de una teoría general del conocimiento ${ }^{39}$. Hay que agregar al debate las dimensiones de la pluralidad de los saberes y su democratización y de una ciudadanía cognitiva.

En sociedades con heterogeneidades estructurales, socioculturales y económicas, con pasado colonial, como las africanas, latinoamericanas y asiáticas, coexisten distintos "modos de producción" y diversidades sociolingüísticas y culturales, a la vez que se identifican las referidas incompatibilidades entre conocimientos científicos, su aplicación y otras formas arraigadas de prácticas materiales y culturales artesanales y tradicionales, particularmente de las poblaciones campesinas, pescadores, indígenas, movimientos sociales urbanos marginados, etc. A su vez, es posible que ocurran también procesos híbridos entre los usos de técnicas y de diagnósticos que, una vez consensuados y evaluados sus efectos, puedan coexistir sin comprometer la existencia y la reproducción social, ecológica, económica y cultural de los modelos de "desarrollo" existentes. De esta manera no hace más sentido considerar estas poblaciones tradicionales en oposición a las modernas, lo que implica reconocer que a la vez que sufren influencia de la racionalidad de mercado, lo que incluye las tecnociencias, pueden indicar otras alternativas en términos de gestión de los recursos naturales, por ejemplo, por medio de sus prácticas y saberes sustentables.

Si hay límites para los saberes culturales, los hay igualmente para los conocimientos científicos; una buena medida para evaluar estos límites es la eficacia contextual y situacional en que los conocimientos y saberes culturales son aplicados. En casi todos los casos, como ya hemos señalado, la ciencia moderna aplicada opera con una racionalidad abstracta y no se interesa por los contextos en los cuales es aplicada. Lo que es válido para algunas circunstancias tiene que generalizarse a todos los $\operatorname{casos}^{40}$. Es así que la ciencia normal es enseñada y practicada.

Para avanzar en esta discusión de cómo se excluyen pero también como se aproximan y se complementan visiones sobre el alcance y el rol de las ciencias y de los demás saberes culturales y posibilidades de diálogo, hemos buscado identificar algunos autores y temas que promueven análisis y propuestas concretas y críticas, en principio en la discusión respecto al 'diálogo de saberes' (Enrique Leff), a la "ecología de las prácticas" (Isabelle Stengers), la "ecologia de saberes" (Boaventura de Sousa Santos) en el contexto de la descolonización del saber (Anibal Quijano, Arturo Escobar, Walter Mignolo...) y de la "interculturalidad" (Fornet-Betancourt) ${ }^{41}$.

Si por un lado los distintos saberes culturales (populares o tradicionales) son transformados por las modalidades científicas (conocimientos y tecnologías aplicadas), estas sufren los efectos de la crítica intelectual de la misma comunidad epistémica, además de la crítica política de los actores sociales involucrados en tales situaciones y prácticas que reivindican su condición de agentes y sujetos (democracia cognitiva) ${ }^{42}$.

Presentamos a continuación algunos ejemplos de cómo es posible aproximar el diálogo de saberes, por

\footnotetext{
${ }^{39}$ John Ziman (2000, p. 56), científico inglés y filósofo de la ciencia nos dice que esta constituye un modo de producción del conocimiento. Sus normas sociales son inseparables de las normas epistémicas, llamadas de "principios reguladores" (regulative principles). Las ideas de los científicos acerca de lo que debe contar como "la verdad" no puede disociarse de los caminos en que juntos la persiguen. La filosofía de la ciencia académica es parte y parcela de su cultura.

40 "El ejemplo siguiente ilustra bien los peligros de sustituir un tipo de conocimiento por otro en base a jerarquías abstractas. En los años de 1960, los sistemas milenarios de irrigación de los campos de arroz en la isla de Bali, Indonesia, fueron sustituidos por sistemas científicos de irrigación, promovidos por los seguidores de la revolución verde. Los sistemas tradicionales de irrigación se basaban en conocimientos hidrológicos, agrícolas y religiosos ancestrales y eran administrados por sacerdotes de un templo hindu-budista dedicado a Dewi-Danu, la deusa del lago. Fueron sustituidos justamente porque eran considerados productos de la magia y de la superstición, derivados de la creencia desvalorizada del 'culto del arroz'. En decorrencia de ello, la sustitución tuvo resultados desastrosos para la cultura de arroz, con bajas en la cosecha para más de la mitad. Los malos resultados en las cosechas siguientes hicieron que se volviese a introducir los sistemas tradicionales" (De Sousa et al., 2005, p. 60-61).

${ }^{41}$ Sin embargo, como se trata de temas que requieren ampliación y profundización de la discusión nos hemos reservado para más adelante esta tarea. En este sentido ver algunos de los trabajos citados: Stengers (1997; 2005), Quijano (2000), Mignolo (2000), Escobar (2000), Fornet-Betancourt (2004), De Souza Santos et al. (2005), Leff (2006), Hobsbawm (2009), De Sousa Santos (2010).

42 "En menos de una generación hemos sido testigos de una transformación radical y irreversible, en todo el mundo en la forma en que la ciencia se organiza, gestiona y realiza... La ciencia se está redefiniendo en todos los niveles, y en relación con otros sectores de la sociedad. Esto es lo que quiero decir cuando digo que la ciencia académica está dando paso a la ciencia post-académica...” (Ziman, 2000, p. 67).
} 
medio de nueva cultura cognitiva entre lo que consideramos una ciencia en tránsito (ciencia post-académica) y la pertinencia de la reinvención de los demás saberes culturales.

\section{Para una práctica dialógica de saberes: ¿hacia una ciencia post-académica? ${ }^{43}$}

Consideremos entonces la comparación entre clases de fenómenos de la realidad, pertinentes en cuanto fenómenos reconocidos públicamente en el ámbito de la relación sociedad y naturaleza, en consecuencia, pertenecientes al campo del ambientalismo o, más específicamente, del socioambientalismo.

Desde el punto de vista de las técnicas del hacer ciencia en cada una de las ramas especializadas del conocimiento, uno puede argumentar que de hecho se está considerando fenómenos semejantes, entre procedimientos científicos y no científicos, lo mismo tratándose de miradas y explicaciones distintas, como por ejemplo, los tipos de explicación que las ciencias agrarias atribuyen a los elementos geofísicos o bioquímicos para analizar la fertilidad de los suelos.

La utilización del análisis de laboratorio y del conocimiento acumulado en geología, química y biología permiten identificar las características del suelo, dentro de un standard de lo que se considera hoy día como criterios de fertilidad para determinado patrón de productividad que exige correcciones y aplicaciones de insumos químicos, en caso de identificar deficiencias en sus elementos básicos. Procediendo de esta manera se obtienen resultados considerados adecuados para este modelo reconocido como científico. Los códigos y operaciones lógicas y matemáticas al interior de cada una de las ciencias de apoyo a las ciencias agrarias forman un cuadro de referencia teórico-conceptual que además de hacer parte de la historia de cada una de esas disciplinas, son transmitidas como ciencias normales en manuales escolares (Kuhn, 1993; Bachelard, 1991) a las generaciones de estudiantes y científicos que serán los guardianes de este conocimiento y de su difusión y aplicación en sus prácticas profesionales y pedagógicas vigentes.

Esta sería una primera parte de la estructura y organización de las disciplinas que, sin embargo, no flotan en el aire y que en su segunda dimensión se articulan de distintas maneras a la dinámica y al funcionamiento de los sistemas sociales en los cuales están insertas y que se vuelven funcionales a los sistemas de reglas, normas y requerimientos productivos del mercado. Es, por así decir, la parte de los usos de las ciencias o de las tecnociencias ubicadas en el núcleo duro del sistema de producción y aplicación de los conocimientos y técnicas científicas.

Una tercera dimensión que hace el puente entre las dos anteriores son los mecanismos de institucionalización y de legitimación social de parte de estas ciencias que necesitan de una instancia política y jurídica en la sociedad, en las organizaciones de control y validación corporativa, en el sistema educacional y en las agencias de investigación y de las demás agencias del Estado.

Veamos ahora cómo ocurre esta triple dimensión en las formas de enunciación y en las prácticas generadas por los conocimientos no científicos o saberes vernáculos en el mismo dominio de la fertilidad de los suelos, de parte de los agricultores agroecológicos que también parten de los conocimientos transmitidos por la tradición, de generación a generación. Sus conocimientos obedecen a un sistema de observación de cómo la vegetación y sus variedades crecen y se adaptan a los suelos, conformando distintos paisajes que permiten a los agricultores identificar así, indirectamente (a ejemplo de los laboratorios en los sistemas convencionales), los distintos tipos de fertilidad de los suelos (Batistela, 2009; Floriani, 2007b).

A ejemplo de los sistemas convencionales, los sistemas vernáculos se utilizan de correctivos para combatir plagas y corregir los suelos poco fértiles, pero con usos de técnicas y productos naturales que los diferencian de los agroquímicos producidos por los laboratorios y que

${ }^{43}$ Empleamos el término de ciencia post-académica (Ziman, 2000) próximo al sentido de ciencia post-normal (Funtowicz \& Ravetz, 1993) y de la pluralidad de los modos de conocimiento de Sousa Santos (2005) es decir, una ciencia que no sea solamente legitimada en la academia o por la corporación científica. Una ciencia que combina distintas epistemologías con saberes culturales, que sea, además, una ciencia pública, pertinente y ciudadana. 
se inscriben en la cadena productiva mercantil, en el cual el sistema científico y las tecnologías productivas coevolucionan ${ }^{44}$ con el sistema de mercado.

Como segunda característica de las prácticas y saberes vernáculos, tenemos que los mismos se inscriben en los bordes del sistema hegemónico pero no menos social y político que este último, es decir, a la vez que busca instituirse como modelo reconocido y legitimado por agentes sociales, lo que incluye parcialmente al Estado reconocer en sus políticas sociales y agrarias el apoyo a la agroecología y a la agricultura familiar, es posible también observar que se trata de un intento de insurgencia y de contestación al sistema dominante de producción y de organización social de sectores rurales y urbanos, toda vez que este movimiento se inscribe igualmente en el contexto de la emergencia de nuevas ruralidades (Nazareth, 2000).

En su tercera dimensión, los sistemas productivos alternativos, vinculados a la agroecología (Altieri, 1995) y a la producción de alimentos de parte de la agricultura familiar, intentan romper el bloqueo establecido por la cultura de producción y consumo dominantes, pues se abren los espacios de contestación de un conjunto de valores que conllevan los sistemas de prácticas, a la vez que se contestan por ejemplo las innovaciones transgénicas, contra las cuales se levantan un conjunto de sospechas e incertidumbres sobre la salud humana y de otras especies animales y vegetales una vez que pone en riesgo no sólo el patrimonio genético natural, sino que de igual manera los sistemas sociales y las culturas de los pueblos originarios y tradicionales. Agregase a estas críticas el derecho de propiedad que detentan las multinacionales sobre el patrimonio genético de los bienes comunes que pertenecen, en principio, a toda la humanidad y no a algunas empresas privadas.

De igual manera, la relación entre formas dominantes de producción y apropiación de la naturaleza y otras alternativas, antes consideradas, permite identificar que se tratan de modelos en conflicto y que develan mecanismos y valores sociales y culturales contradictorios, lo que permite vislumbrar los límites y potencialidades de ambos modelos.
Sin embargo, lo que está en juego entre la elección de los sistemas productivos y de los estilos de vida en el caso de la agroecología y la producción de formas no contaminantes de alimentos es de otro orden, es decir, de un sistema de poder hegemónico del mercado que impone unilateralmente un modelo de producción y de consumo. Las preguntas que quedan en el aire sobre esta cuestión son: ¿cómo el medio ambiente aparece como un signo negativo de la modernidad?, y esto, ¿haría cambiar los estilos de vida y los sistemas de producción y consumo?

Hay algunas respuestas que pueden presentarse: algunas optimistas (o hasta ingenuas) y otras pesimistas (o hasta catastróficas); dentro del rango de las primeras se encuentra el rol de la educación y del control social ejercido por ciudadanos y colectivos en un contexto de sistemas sociales y políticos democráticos; en el dominio de las respuestas negativas se encuentran las de los escépticos que sólo creen que la humanidad no siempre aprende con sus errores y que solamente cuando la naturaleza se toma venganza de los malos tratos que recibe por la acción depredadora humana es que se buscarán algunas salidas. La escasez del agua, la desertificación, la superpoblación del planeta y las ciudades insostenibles son algunos signos de esta segunda vía. Posiblemente será necesario considerar el camino del medio entre ambos tipos de respuesta, en que se encuentran los avisos de la naturaleza, el sentido de responsabilidad de Estados y ciudadanos y la generosidad de muchos que desde sus sitios de resistencia y de búsqueda de alternativas nos enseñan a buscar algunas luces al final del túnel.

Pero, ¿qué es efectivamente y cómo se accede a este "camino del medio"? Estamos seguros de que el planteamiento de estas preguntas no es una cuestión meramente retórica y que los problemas que señalan deben ser necesariamente abordados.

\section{A modo de conclusión}

Hemos llegado a señalar, como punto de partida, una hipótesis general capaz de determinar, en términos

${ }^{44}$ Para la discusión del concepto de coevolución, consultar (Redclift \& Woodgate, 1998). 
heurísticos, si y como lo que designamos por "situación cultural" está en la base de los condicionantes de factores socio históricos que definen las manifestaciones del pensamiento y por ende de su creación por las distintas formas de institucionalidad, sean las de orden del pensamiento científico ( por cuenta de las modernas agencias de investigación y de la formación educacional) como de los demás conocimientos, culturalmente arraigados ( desde las múltiples manifestaciones culturales) y que pueden ser analizados por algunas teorías, en las cuales emergen los estudios de los imaginarios.

El punto de partida lo situamos igualmente en las controversias sobre los problemas socioambientales que comparten los síntomas de una crisis del pensamiento y del racionalismo moderno, cruzado por interposiciones y contraposiciones de epistemologías de la diversidad desde el Sur.

Desde la primera sección, hemos indicado que el conocimiento es siempre conocimiento de algo y ese algo es con relación a alguien, además de un pensamiento situado, lo que hace de la intencionalidad una relación compleja. En el contexto lógico y concreto, esa relación debe ser tratada desde las correlaciones y sus interdependencias, más allá de la determinación causal, pues no se trata de relación mecánica (de pura causa y efecto) pero de mecanismos de recursividad, cuya expresión es la red, más que de una cadena lineal. Es el mundo de la historicidad que condiciona los cambios de los fenómenos socioculturales en los cuales se ubican los cambios de la idea práctica de la ciencia y de los objetos científicos.

De tal manera que el pensamiento complejo rechaza los paradigmas de la simplicidad, sus mecanismos lógicos binarios, basados en las disyunciones y en las segmentaciones aisladas de la realidad, cuya representación actual más evidente está estampada en la moderna cartografía de las ciencias disciplinares. De idéntica manera que no se acepta la vieja distinción y el valor atribuido a lo objetivo frente a lo subjetivo, o viceversa, por distintas concepciones filosóficas del mecanicismo y del idealismo.

Una vez que nada surge en el vacío conceptual, o cultural y que la realidad no se autodefine desde sí misma, es necesario utilizarse de recursos hermenéuticos, de teorías y métodos para develar los varios sentidos que atribuimos a lo que consideramos relevante y pertinente, por medio de los usos de teorías, prácticas de reglas y juegos de lenguaje, a las que cabe agregar cuestiones de imaginarios, como la ideología, la utopía y las representaciones del sentido común. Se añade a este tema la admisión de que el tratamiento de los modelos conceptuales y las nuevas prácticas de su elaboración se encuentran en las denominadas ciencias post-normales, y que según nuestro parecer se encuentran en tránsito hacia nuevas identidades cognocitivas; es decir, procesos concebidos actualmente como alternativos y reconocidos como multi/inter/trans-disciplinarios.

Así y en base a estos planteamientos de trasfondo, desde la segunda sección nos hemos abocado a responder algunos interrogantes acerca de lo que constituye un problema socioambiental, a la vez que buscamos dar cuenta de algunas de sus varias concepciones, lo que incluye aquellas que parten del pensamiento complejo.

Es la presencia y la interrelación de múltiples factores cognitivos, políticos, culturales, económicos, tecnológicos, identitarios... que permiten reunir en un entramado de situaciones teóricas pero igualmente prácticas, las nuevas estrategias de interpretación y de construcción de los problemas socioambientales.

Así, la cuestión socioambiental gana espacios en la política cuando intenta significar la discusión en torno al desarrollo sustentable o sustentabilidad, mediante la confrontación de visiones, valores e interpretaciones sobre el sentido de naturaleza, de su instrumentalización por el mercado; de igual forma por la violencia de los procesos de expropiación de los territorios, de resistencias y conflictos que tienen cabida en los enfrentamientos sociales, y que ganan espacio en las universidades, sindicatos, organizaciones no gubernamentales, además de generar efectos en la organización política y en las formas de apreciación cultural de los actores subalternos que resignifican sus pertenencias, identidades y derechos interculturales.

Tampoco hay cómo rehacer el camino de la construcción de un pensamiento genuinamente socioambiental sino por la crítica radical a los fundamentos epistemológicos de la idea de ciencia, de su reinvención, de sus prácticas y de una ética de su pertinencia y a quiénes y para qué sirve. Sin una crítica a los modelos productivistas, de la sobre economización de las relaciones sociales, del hiperconsumo y del despilfarro de los 
recursos naturales finitos, no hay cómo acceder a nuevas resignificaciones. De ahí es posible aproximar una epistemología de la diversidad a una epistemología política y por la apuesta en una nueva racionalidad ambiental que no sea meramente contemplativa pero proactiva, hacia nuevos derroteros, mismo que sepamos que la realidad es un complejo proceso que se desdobla en novedades y emergencias no exentas de contradicciones e incertidumbres.

Para ello hay que partir de la constatación de que las resistencias epistémicas surgen desde Latinoamérica con la reemergencia de los saberes culturales y de las etnociencias, por los pueblos originarios y las poblaciones tradicionales, abriendo importantes caminos hacia diálogos de saberes interculturales. Nos hemos planteado cuestiones desde esta novedad y si es posible establecer un nuevo contrato epistemológico entre los saberes científicos con los no científicos. Además de establecer un paralelo con los procesos de fabricación del conocimiento entre distintas perspectivas de las ciencias convencionales y de las etnociencias, tomamos como ejemplo los diagnósticos sobre la fertilidad de los suelos. Con este ejemplo, planteamos la posibilidad de coexistencias y complementariedades entre distintas maneras de producir conocimientos, muy de acuerdo a una epistemología de la diversidad, pues el pensamiento complejo depende de la diversidad para garantizar su creatividad.

Por último, creemos que los interrogantes que hemos presentado en este texto y las estrategias argumentativas utilizadas, nos han permitido dibujar algunas líneas para seguir con una mirada y un planteamiento capaz de generar discusiones, ojalá pertinentes, para un diálogo fecundo con todos los que se han puesto los mismos desafíos.

\section{Referencias}

Altieri, M. The science of sustainable agriculture. Boulder: Westview Press, 1995.

Argueta Villamar, A. Conocimiento tradicional, innovación y reapropriación social. México: Siglo XXI, 2012.

Bachelard, G. La formación del espiritu científico. Contribución a un psicoanálisis del conocimiento objetivo.17. ed. México: Siglo XXI, 1991.

Batistela, E. M. Agroecologia e racionalidade ambiental: a mediação social do CAPA e a reconstrução agroecológica no sudoeste paranaense. Curitiba, Tesis (Doctorado en Sociología) - Universidade Federal do Paraná, 2009.

Beck, U. Sociedade de risco. Rumo a uma outra modernidade. São Paulo: Editora 34, 2010.

Bengoa, J. La emergencia indigena en América Latina. México: FCE, 2000.

Burawoy, M. Por uma sociologia pública. Política y Sociedad, 42(1), 197-222, 2005.

Capra, F. El punto crucial. Buenos Aires: Troquel, 2008.

Capra, F. La trama de la vida. Barcelona: Editorial Anagrama, 2012.
Castoriadis, C. Figuras de lo pensable. México: Fondo de Cultura Económica, 2002.

Castoriadis, C. Los dominios del hombre. Barcelona: Gedisa, 2005.

Castoriadis, C. Una sociedad a la deriva. Buenos Aires: Katz Editores, 2006.

Castoriadis, C. La institución imaginaria de la sociedad. Buenos Aires: Tusquets, 2007.

Deleuze, G. Conversações, 1972-1990. São Paulo: Editora 34, 1992.

Deleuze, G.; Guattari, F. El Anti Edipo. Barcelona: Paidós, 2004.

Echeverría, J. La revolución tecnocientífica. CONfines, 1/2, agosto-diciembre 2005.

Encabo, J. V. Sujetos, objetividad y razón pública. La ciencia y sus sujetos. ¿Quiénes hacen la ciencia en el siglo XXI? México: Siglo XXI, 2009.p.34-56.

Escobar, A. Biodiversidad, naturaleza y cultura: localidad y globalidad en las estrategias de conservación. México: UNAM, 1997. 
Escobar, A. El lugar de la naturaleza y la naturaleza del lugar: ¿globalización o postdesarrollo?. In: Lander, E. (Comp.). La colonialidad del saber: eurocentrismo y ciencias sociales. Perspectivas latinoamericanas. La Habana: Editorial de Ciencias Sociales, 2005.p. 115-151.

Fairclough, N. Discurso e mudança social. Brasília: Editora UnB, 2008. Reimpresión.

Floriani, D. Pós-Modernidade, crise cultural e emergências cognitivas. Ideação (Unioeste. Impresso), 13, 181-200, 2011.

Floriani, D. Nuevos sentidos para una ciencia socioambiental desde la perspectiva del pensamiento complejo. Lider, Osorno, 24, 9-31, 2014.

Floriani, D. Diálogo de Saberes. In: Ferraro Jr., L. A. (Org.). Caminhos e encontros: formação de educadoras(es) ambientais e coletivos educadores. 1. ed., v. 2. Brasília: MMA, Depto.de Educação Ambiental, p. 105-116, 2007.

Floriani, N. Avaliação das terras pelos agricultores ecológicos de Rio Branco do Sul - PR. Curitiba, Tesis (Doctorado en Medio Ambiente y Desarrollo - MADE) - Universidade Federal do Paraná, 2007.

Foucault, M. L'Archeologie du savoir. Paris: Gallimard, 1969.

Foucault, M. Defender la sociedad. México: F.C.E., 2006.

Foucault, M. El poder, una bestia magnifica. México: Siglo XXI Editores, 2012.

Fornet-Betancourt, Raúl (Comp.). Crítica intercultural de la Filosofia latinoamericana actual. Madrid: Editorial Trotta, 2004

Funtowicz, S. O.; Ravetz, J. R. Science for the Post-Normal Age. Futures, 25(7), 739-755, 1993.

Freud, S. Psicologia das massas e análise do eu e outros textos. São Paulo: Companhia das Letras, 2011.

Giddens, A. A modernidade sob um signo negativo: questões ecológicas e políticas da vida. Para além da esquerda e da direita. São Paulo: Unesp, 1997.

Guattari, F. Revolução molecular. São Paulo: Brasiliense, 1982.

Jacob, F. La lógica de lo viviente. Santiago de Chile: Editorial Universitaria, 1972.

Koyré, A. Estudios galileanos. México: Siglo XXI Editores, 1981.

Koyré, A. Pensar la ciencia. Barcelona: Ediciones Paidós Ibérica, 1994.
Kuhn, T. La estructura de las revoluciones cientificas. Santiago de Chile: F.C.E., 1993.

Kuhn, T. ¿Qué son las revoluciones científicas? Barcelona: Ediciones Paidós, 1999.

Latour, B. Políticas da natureza: como fazer ciência na democracia. Bauru, SP: EDUSC, 2004.

Leff, E. Racionalidad ambiental. La reapropiación social de la naturaleza. México: Siglo XXI Editores, 2004.

Leff, E. Aventuras de la epistemología ambiental. 2. ed. México: Siglo XXI Editores, 2007.

Leff, E. Discursos sustentables. México: Siglo XXI Editores, 2008.

Longino, H. Epistemologia feminista. In: Greco, J.; Sosa, E. (Orgs.). Compendio de Epistemologia. São Paulo: Edições Loyola, 2008. p. 505-546.

Maturana, H.; Varela, F. El árbol del conocimiento. Santiago de Chile: Editorial Universitaria, 2007.

Monod, J. El azar y la necesidad. Barcelona: Editorial Planeta-D’Agostini, 1993.

Morin, E. Ciencia con consciencia. Barcelona: Anthropos, 1982.

Morin, E. El pensamiento ecologizado. Gazeta de Antropología, 12, 1996 (versión en línea).

Morin, E. Introducción al pensamiento complejo. Barcelona: Gedisa, 2003.

Ortega y Gasset, J. Historia como sistema. Madrid: Edit. Rev. De Occ., 1962a. (Col. El Arquero).

Ortega y Gasset, J. Pasado y porvenir para el hombre actual. Madrid: Revista de Occidente, S.A., 1962 b.

Ortega y Gasset, J. El hombre y la Gente. Madrid: Edit. Rev. De Occ., 1962c. (Col. El Arquero).

Ortega y Gasset, J. Origen y epílogo de la filosofía. Madrid: Rev. de Occidente, 1972. (Col. El Arquero).

Ortega y Gasset, J. El tema de nuestro tiempo. Madrid: Revista de Occidente, en Alianza Editorial S.A., 1981.

Popper, K. Conjeturas y refutaciones. El desarrollo del conocimiento científico. 2. ed. Buenos Aires: Paidós, 1983.

Popper, K. Conocimiento objetivo. Madrid: Tecnos, 1992.

Prigogine, I; Stengers, I. La nueva alianza. Metamorfosis de la ciencia. Madrid: Alianza Editorial, 2004. Cuarta reimpresión. 
Redclift, M.; Woodgate, G. De una sociología de la naturaleza a una sociología ambiental: más allá de la construcción social. Revista Internacional de Sociología, 19-20, 15-40, 1998.

Ricoeur, P. Ideología y utopía. Barcelona: Gedisa, 2001.

Rojo, G. Globalización e identidades nacionales y postnacionales... ¿De qué estamos hablando? Santiago: LOM, 2006.

Santos, B. de S. Para uma sociologia das ausências e uma sociologia das emergências. Conhecimento prudente para uma vida decente. São Paulo: Cortez, 2004.p. 777-821.

Santos, B. de S. Conocer desde el Sur. La Paz, Bolivia: CLACSO, CIDES-UMSA, Plural Editores, 2007.

Santos, B. de S. Descolonizar el saber, reinventar el poder. Montevideo: Trilce, 2010.

Santos, B. de S.; Meneses, M. P. G. de; Nunes, J. A. Introdução: Para ampliar o cânone da ciência: a diversidade epistemológica do mundo. In: Sousa, B. de S. (Org.). Semear outras soluções: os caminhos da biodiversidade e dos conhecimentos rivais. Rio de Janeiro: Civilização Brasileira, 2005. p. 21-121.

Sartre, J. P. El hombre y las cosas. Buenos Aires: Losada, 1961.

Searle, J. La construcción de la realidad social. Barcelona: Ediciones Paidós Ibérica, 1997.
Stengers, I. A invenção das ciências modernas. São Paulo: Editora 34, 2002.

Toledo, V.; Barrera-Bassols, N. La memoria biocultural: la importancia ecológica de las sabidurías tradicionales. Barcelona: Icaria Editorial, 2008.

Varela, F. El fenómeno de la vida. Santiago de Chile: Dolmen Ediciones, 2000.

Varela, F. et al. De cuerpo presente. Barcelona: Gedisa, 2011.

Vergara, N. Significación social y territorio: aproximaciones metodológicas.Terra@Plural,5(2),169-178, 2011.

Vergara, Nelson. Significación social y territorio: aproximaciones epistemológicas. Revista Lider, 21, 9-18, 2012.

Wanderley, M. N. B. A emergência de uma nova ruralidade nas sociedades modernas avançadas. O "rural" como espaço singular e ator coletivo. Estudos Sociedade e Agricultura, Rio de Janeiro, 15, 87-145, 2000.

Watzlawick, P. El ojo del observador. Contribuciones al constructivismo. Barcelona: Gedisa, 1994.

ZIMAN, John. Real Science - what it is, and what it means. Cambridge: Cambridge University Press, 2000. 